\title{
Quantitative and Depth-Resolved Investigation of Deep-Level Defects in InGaN/GaN Heterostructures
}

\author{
A. ARMSTRONG, ${ }^{1,2}$ M.H. CRAWFORD, ${ }^{1}$ and D.D. KOLESKE ${ }^{1}$ \\ 1.-Sandia National Laboratories, Albuquerque, NM 87185, USA. 2.-e-mail: aarmstr@sandia.gov
}

\begin{abstract}
Deep-level defects in $\operatorname{In}_{0.17} \mathrm{Ga}_{0.83} \mathrm{~N} / \mathrm{In}_{0.02} \mathrm{Ga}_{0.98} \mathrm{~N} / p$-GaN:Mg heterostructures were studied using deep-level optical spectroscopy (DLOS). Depth-resolved DLOS was achieved by exploiting the polarization-induced electric fields to discriminate among defects located in the $\operatorname{In}_{0.17} \mathrm{Ga}_{0.83} \mathrm{~N}$ and the $\mathrm{In}_{0.02} \mathrm{Ga}_{0.98} \mathrm{~N}$ regions. Growth conditions for the $\mathrm{In}_{x} \mathrm{Ga}_{1-x} \mathrm{~N}$ layers were nominally the same as those in InGaN/GaN multi-quantum-well (MQW) structures, so the defect states reported here are expected to be active in MQW regions. Thus, this work provides important insight into defects that are likely to influence MQW radiative efficiency. $\mathrm{In}_{0.17} \mathrm{Ga}_{0.83} \mathrm{~N}$-related bandgap states were observed at $E_{\mathrm{v}}+1.60 \mathrm{eV}$ and $E_{\mathrm{v}}+2.59 \mathrm{eV}$, where $E_{\mathrm{v}}$ is the valence-band maximum, compared with levels at $E_{\mathrm{v}}+1.85 \mathrm{eV}, E_{\mathrm{v}}+2.51 \mathrm{eV}$, and $E_{\mathrm{v}}+3.30 \mathrm{eV}$ in the $\mathrm{In}_{0.02} \mathrm{Ga}_{0.98} \mathrm{~N}$ region. A lighted capacitance-voltage technique was used to determine the areal density of deep states. The possible origins of the associated defects are considered along with their potential roles in light-emitting diodes.
\end{abstract}

Key words: Deep level, compound semiconductor, InGaN

\section{INTRODUCTION}

Blue- and green-emitting InGaN-based lightemitting diodes (LEDs) are of interest for a variety of applications, including solid-state lighting. ${ }^{1}$ The radiative efficiency of InGaN LEDs is expected to be limited in part by the deleterious impact of defects. Defects impact the radiative efficiency of quantum wells (QWs) by introducing deep levels in the bandgap that can serve as nonradiative recombination centers (NRCs). Despite extensive scrutiny, few deep-level defects have been identified for InGaN films, and their impact on InGaN/GaN QW internal quantum efficiency (IQE) is not fully understood.

One approach to studying InGaN defects has been to investigate InGaN/GaN LEDs as a whole. This method presents the difficulty of detecting defects that are associated with the thin $(\sim 3 \mathrm{~nm})$ InGaN wells and discerning them from defects located in the thicker GaN barriers $(\sim 10 \mathrm{~nm})$ or $n$-type or $p$-type GaN regions (>100 nm). For example, a

(Received August 6, 2010; accepted November 16, 2010; published online December 24, 2010) decrease in the photocurrent of an InGaN/GaN LED after electrical stressing has been attributed to the generation of NRCs in the $\mathrm{QW}$ region, though the putative defects themselves were not observed or identified. ${ }^{2}$ Techniques such as deep-level transient spectroscopy (DLTS) combined with capacitancevoltage $(C-V)$ profiling provide some depth resolution to identify QW defect states in LEDs. ${ }^{3,4}$ However, previous DLTS investigations were unable to discern between deep-level defects associated with InGaN quantum wells or nearby $\mathrm{GaN}$ regions. $^{3}$ In addition to ambiguous spatial resolution, application of DLTS to InGaN/GaN LEDs suffers other drawbacks. The thermal instability of InGaN wells limits the maximum temperature of DLTS to a range that precludes the investigation of deep levels near the middle of the InGaN bandgap, where NRCs are most active. Also, quantitative assessment of the defect density is not possible via DLTS due to the rapidly spatially varying free carrier concentration in the MQW region. ${ }^{4}$

InGaN epilayers grown on GaN have been studied for clearer InGaN-related defect identification, though the InGaN epilayers were most likely partially strain-relaxed., 6 Cathodoluminescence 
(CL) investigation of $\operatorname{In}_{x} \mathrm{Ga}_{1-x} \mathrm{~N}$ films of $100 \mathrm{~nm}$ thickness and $0.08 \leq x \leq 0.17$ revealed defect bands approximately $0.3 \mathrm{eV}$ below the main emission peak $^{5}$ that were attributed to surface features associated with threading dislocations, though neither the defect level energy nor density could be obtained. DLTS study of a 200 -nm-thick $\operatorname{In}_{0.14} \mathrm{Ga}_{0.86} \mathrm{~N}$ epilayer grown on $\mathrm{GaN}$ with a sapphire template revealed a deep level at $E_{\mathrm{c}}-0.40 \mathrm{eV}^{6}$ but could not probe defect levels lying near mid-bandgap or the minority-carrier band edge. While the study of InGaN epilayers unambiguously identifies InGaNrelated defects, the thickness of the InGaN films of Refs. 5 and 6 are more than an order of magnitude or greater than that of typical InGaN well regions in QWs and may be subject to strain relaxation. It is not clear, then, if the growth conditions or film quality of the thicker InGaN epilayers are comparable to those of nanoscopic InGaN wells.

In light of previous work, quantitative defect spectroscopy with sufficient depth resolution to discriminate among defects residing in the InGaN well and GaN barrier of a QW structure has yet to be demonstrated. To this end, we have implemented deep-level optical spectroscopy (DLOS), ${ }^{7}$ a differential photocapacitance technique, to study deep-level defects in coherently strained InGaN heterostructures. The InGaN cap layer of the heterostructure was grown under nominally the same conditions as InGaN well layers of InGaN/GaN MQWs to assess the nature and potential role of InGaN-related defects in QW radiative efficiency. Depth-resolved DLOS of InGaN heterostructures was achieved by exploiting the polarization-induced electric fields to selectively distribute DLOS sensitivity among the InGaN cap that mimics the well of a MQW structure or the underlying layers. The defect density was measured using the lighted capacitance-voltage (LCV) method. ${ }^{8}$

This work is organized as follows. The "Device Simulation" section presents one-dimensional Schrödinger-Poisson (1D-SP) simulations that indicate the heterostructure required to achieve depth sensitivity of DLOS. The "Experimental Procedures" section details the growth and device processing of the DLOS samples and the experimental conditions of the measurements. Electrical characterization of DLOS samples is discussed in the "Diode Characterization" section. The "Optical Spectroscopy of Defects" and "Determination of Deep-Level Density" sections present the experimental DLOS and LCV results, respectively. The physical origins and potential roles of the observed defects are discussed in the "Discussion" section. The "Conclusions" section offers a summary and conclusions.

\section{DEVICE SIMULATION}

Using a 1D-SP simulator ${ }^{9}$ to calculate band diagrams, a suitable combination of indium content, layer thickness, and doping profile was determined to achieve depth sensitivity of DLOS. The simulated structure was grown along the $\langle 0001\rangle$ axis and consisted of a 12-nm-thick unintentionally doped (UID) $\mathrm{In}_{0.17} \mathrm{Ga}_{0.83} \mathrm{~N}$ capping layer upon a $200-\mathrm{nm}$ thick UID $\mathrm{In}_{0.02} \mathrm{Ga}_{0.98} \mathrm{~N}$ underlayer (UL) upon a p-type GaN:Mg template. Values for the spontaneous and piezoelectric polarization charges were taken from Ref. 10 using linear interpolation between $\mathrm{InN}$ and GaN. Figure 1 shows the band diagram along with the calculated free hole concentration (p) profile for the $\mathrm{In}_{0.17} \mathrm{Ga}_{0.83} \mathrm{~N} / \mathrm{In}_{0.02} \mathrm{Ga}_{0.98} \mathrm{~N} / \mathrm{GaN}$ : $\mathrm{Mg}$ heterostructure at $0 \mathrm{~V}$ and $-2 \mathrm{~V}$ bias. A Schottky barrier $(\Phi)$ of $0.5 \mathrm{eV}$ relative to the valenceband maximum $\left(E_{\mathrm{v}}\right)$ was assumed, because the exact value of $\Phi$ could not be determined experimentally from electrical measurements due to diode nonidealities. Different values of $\Phi$ ranging from $0.5 \mathrm{eV}$ and $1.2 \mathrm{eV}$ were simulated but produced no effect to change the following interpretations or conclusions regarding depth-sensitive DLOS. The influence of residual acceptor and donor concentrations ranging between $1 \times 10^{14} \mathrm{~cm}^{-3}$ and $1 \times$ $10^{16} \mathrm{~cm}^{-3}$ in the UID InGaN regions on the calculated band diagrams was simulated. These levels of background dopants had no discernible effect on the band diagram or free carrier distribution due to the dominance of the polarization charges and $\mathrm{Mg}$ doping in the $p$-GaN region.

This heterostructure was designed to use electrical bias to control which InGaN regions are accumulated with free holes. Such control enables DLOS depth resolution, because DLOS is only sensitive to regions that are depleted of free carriers. From Fig. 1 , at $0 \mathrm{~V}$, this includes only the $\mathrm{In}_{0.17} \mathrm{Ga}_{0.83} \mathrm{~N}$ cap. Despite the lack of $\mathrm{Mg}$ doping in the $\mathrm{In}_{0.02}$ $\mathrm{Ga}_{0.98} \mathrm{~N} \mathrm{UL}$, the bands are nearly flat, and there is strong hole accumulation due to the two-dimensional hole gases (2DHGs) formed on either side at the $\mathrm{In}_{0.17} \mathrm{Ga}_{0.83} \mathrm{~N} / \mathrm{In}_{0.02} \mathrm{Ga}_{0.98} \mathrm{~N}$ and $\mathrm{In}_{0.02} \mathrm{Ga}_{0.98} \mathrm{~N} / p$ GaN:Mg heterointerfaces. The 2DHG charge can be balanced by ionized acceptors at the surface and/or ionized $\mathrm{Mg}$ acceptors in the GaN. No free electron accumulation is required to maintain charge balance. The abundance of free holes available for thermal capture at the $\mathrm{In}_{0.17} \mathrm{Ga}_{0.83} \mathrm{~N} / \mathrm{In}_{0.02} \mathrm{Ga}_{0.98} \mathrm{~N}$ and $\mathrm{In}_{0.02} \mathrm{Ga}_{0.98} \mathrm{~N} / \mathrm{GaN}: \mathrm{Mg}$ heterointerfaces and in the $\mathrm{In}_{0.02} \mathrm{Ga}_{0.98} \mathrm{~N}$ UL and $p$-GaN:Mg layers quenches DLOS response in these regions at $0 \mathrm{~V}$. Thus, the DLOS spectrum at $0 \mathrm{~V}$ should be dominated by defects located in the $12-\mathrm{nm} \mathrm{In}_{0.17} \mathrm{Ga}_{0.83} \mathrm{~N}$ cap, even though the $\mathrm{In}_{0.02} \mathrm{Ga}_{0.98} \mathrm{~N}$ and $p$-GaN:Mg layers are much thicker. The physical mechanism for photocapacitance during DLOS at $0 \mathrm{~V}$ is an increase of the space charge of the $\operatorname{In}_{0.17} \mathrm{Ga}_{0.83} \mathrm{~N}$ cap due to defect photoemission, which is reflected as an increase in the $2 \mathrm{DHG}$ capacitance.

Defect levels in the $\operatorname{In}_{0.02} \mathrm{Ga}_{0.98} \mathrm{~N}$ UL can also be investigated by performing DLOS under reverse bias. As shown in Fig. 1, a sufficiently large reverse bias ( $-2 \mathrm{~V}$ in this case) dissipates the 2DHG nearest 

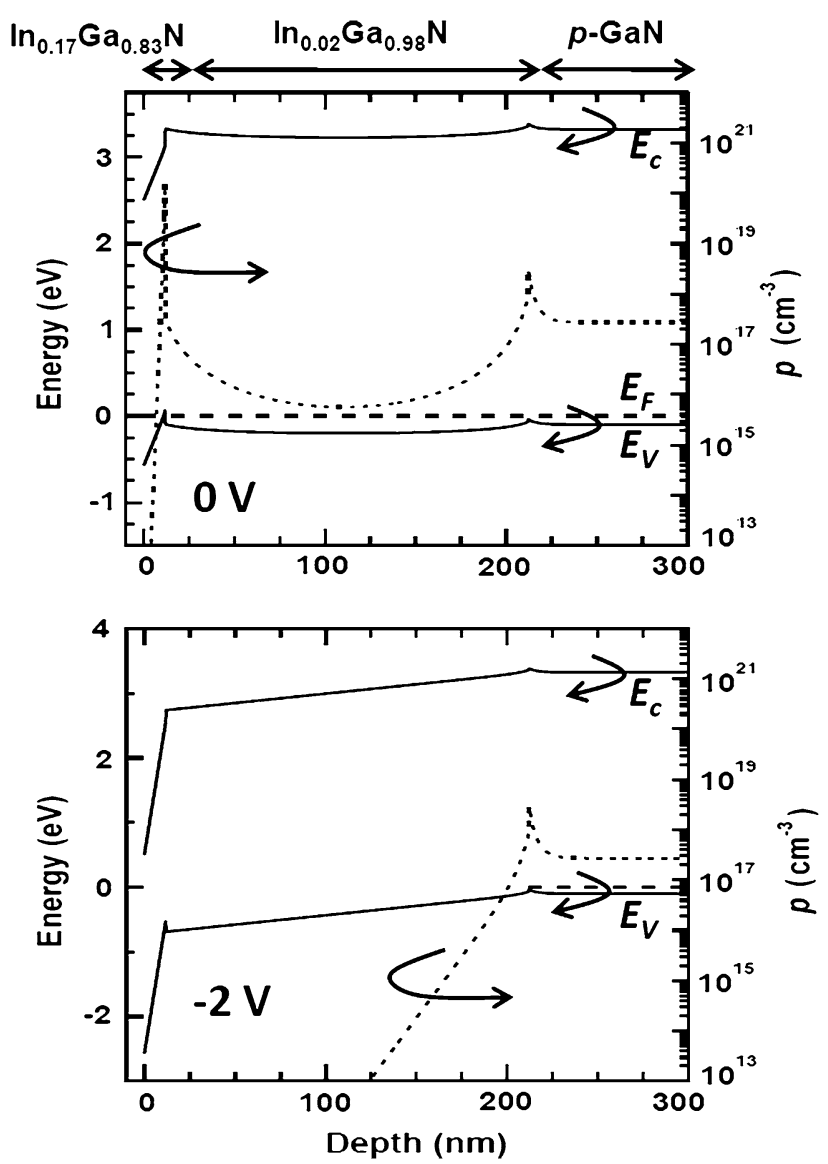

Fig. 1. Calculated band diagrams and free hole concentrations of an $\mathrm{In}_{0.17} \mathrm{Ga}_{0.83} \mathrm{GaN} / \mathrm{In}_{0.02} \mathrm{Ga}_{0.98} \mathrm{~N} / p$-GaN:Mg heterostructure as a function of applied bias.

to the surface and depletes both the $12-\mathrm{nm} \mathrm{In}_{0.17}$ $\mathrm{Ga}_{0.83} \mathrm{~N}$ cap and the 200-nm $\mathrm{In}_{0.02} \mathrm{Ga}_{0.98} \mathrm{~N}$ UL of holes.* The depletion capacitance of the thicker $\mathrm{In}_{0.02} \mathrm{Ga}_{0.98} \mathrm{~N}$ UL now dominates the diode capacitance, so defect photoemission in the $\operatorname{In}_{0.02} \mathrm{Ga}_{0.98} \mathrm{~N}$ UL dominates the DLOS spectrum. DLOS selectivity to defects located in the $\mathrm{In}_{0.02} \mathrm{Ga}_{0.98} \mathrm{~N}$ UL can be further enhanced under reverse bias if the thickness of the $\operatorname{In}_{0.17} \mathrm{Ga}_{0.83} \mathrm{~N}$ cap layer is also reduced. However, the $\operatorname{In}_{0.17} \mathrm{Ga}_{0.83} \mathrm{~N}$ cap layer should not be completely removed, or else the depletion region would extend beyond the $\mathrm{In}_{0.02} \mathrm{Ga}_{0.98} \mathrm{~N}$ UL and into the $p$-GaN:Mg region and complicate DLOS analysis.

The physical location of the observed deep-level defects can then be determined by comparing the

\footnotetext{
*A bias of $-2 \mathrm{~V}$ was the largest reverse bias that could be accurately simulated, because the $1 \mathrm{D}-\mathrm{SP}$ solver is subject to artificial accumulation of carriers at the surface at large reverse bias. Further increase of the reverse bias would only induce greater voltage drop and band bending in the $\mathrm{In}_{0.02} \mathrm{Ga}_{0.98} \mathrm{~N}$ region (and negligible depletion into the heavily doped $p$-GaN region), producing no change in the analysis.
}

DLOS spectra taken at $0 \mathrm{~V}$ to emphasize the 12-nm $\operatorname{In}_{0.17} \mathrm{Ga}_{0.83} \mathrm{~N}$ layer and at reverse bias to emphasize the 200-nm $\operatorname{In}_{0.02} \mathrm{Ga}_{0.98} \mathrm{~N}$ UL. The $p$-GaN:Mg layer remains in the flat-band condition irrespective of the applied bias, and defects associated with this layer are not expected to contribute to the DLOS response. The importance of the $\mathrm{Mg}$ doping in the GaN template becomes apparent by considering that a UID GaN template would be depleted at both equilibrium and large reverse bias. Deep levels in the UID GaN region would then contribute to the DLOS spectra at both biases. This would compromise the selectivity to the $\mathrm{In}_{0.17} \mathrm{Ga}_{0.83} \mathrm{~N}$ layer at $0 \mathrm{~V}$ and complicate the delineation of deep levels among the heterostructure regions.

\section{EXPERIMENTAL PROCEDURES}

InGaN heterostructures were grown on $p$-type GaN templates using metalorganic chemical vapor deposition (MOCVD) in a Veeco D125 short-jar reactor. The $p$-GaN templates were grown at 200 Torr and $1050^{\circ} \mathrm{C}$ using trimethylgallium and $\mathrm{NH}_{3}$ in $\mathrm{H}_{2}$ and $\mathrm{N}_{2}$ on (0001)-oriented sapphire. Following the GaN film coalescence, the GaN was Mg-doped using bis-methylcyclopentadienyl-magnesium at a growth temperature of $970^{\circ} \mathrm{C}$. After a 5 -min anneal in $\mathrm{N}_{2}$ at $850^{\circ} \mathrm{C}, p$-GaN:Mg templates had a hole concentration of $p \approx 2.5 \times 10^{17} \mathrm{~cm}^{-3}$ as determined by Hall-effect measurements. To avoid $\mathrm{Mg}$ memory effects in the InGaN films, the $p$-GaN:Mg films were grown separately and removed from the MOCVD system, after which the MOCVD system was baked to $1050^{\circ} \mathrm{C}$ in $\mathrm{H}_{2}$, followed by reloading the $p$-GaN template wafers for InGaN growth. To reduce $\mathrm{Mg}$ contamination between the $p-\mathrm{GaN}: \mathrm{Mg}$ and the $\mathrm{In}_{0.02} \mathrm{GaN}_{0.98} \mathrm{~N}$ film, the $p-\mathrm{GaN}: \mathrm{Mg}$ wafers were heated in $\mathrm{NH}_{3}$ and carrier gases up to $950^{\circ} \mathrm{C}$ prior to InGaN growth.

InGaN growth proceeded at 300 Torr by adding trimethylindium (TMIn) to the GaN growth and removing the $\mathrm{H}_{2}$ carrier gas. The $\mathrm{In}_{0.02} \mathrm{GaN}_{0.98} \mathrm{~N}$ UL was grown at $880^{\circ} \mathrm{C}$, while the $\mathrm{In}_{0.17} \mathrm{Ga}_{0.83} \mathrm{~N}$ cap was grown at $\sim 760^{\circ} \mathrm{C}$. Inclusion of an $\mathrm{In}_{0.02-}$ $\mathrm{Ga}_{0.98} \mathrm{~N}$ UL is representative of InGaN ULs employed in InGaN/GaN MQWs for improved IQE. ${ }^{11}$ Two InGaN heterostructures were grown on $p$ GaN:Mg templates under conditions nominally identical to MQWs. The first DLOS heterostructure (sample A) consisted of a 12.5-nm-thick $\operatorname{In}_{0.17-}$ $\mathrm{Ga}_{0.83} \mathrm{~N}$ cap layer, which represents the optically active well layer of a MQW structure, grown on top of a $\sim 200$-nm-thick UID $\operatorname{In}_{0.02} \mathrm{Ga}_{0.98} \mathrm{~N}$ UL. A second InGaN heterostructure (sample B) was grown under nominally identical conditions to sample A, except that the cap layer was only $\sim 4 \mathrm{~nm}$ thick. The indium concentration and thickness of the InGaN layers were obtained for both heterostructures using dynamical diffraction analysis of (0002) $\mathrm{x}$-ray diffraction rocking curves. X-ray analysis 
confirmed the targeted indium content and thickness of the InGaN layers, assuming coherent strain.

Schottky diode test devices were fabricated to facilitate DLOS measurements. Semitransparent nickel contacts of $9 \mathrm{~nm}$ thickness were used for the Schottky metal. Ohmic contacts were formed by scoring alleys into the bare InGaN surface using a diamond scribe and pressing indium into the alleys. The indium likely forms a lateral contact with access to the $p$-type GaN:Mg layer and the 2DHG that is expected to form at the $\operatorname{In}_{0.17} \mathrm{Ga}_{0.83} \mathrm{~N} / \mathrm{In}_{0.02^{-}}$ $\mathrm{Ga}_{0.98} \mathrm{~N}$ heterointerface.

DLOS, current-voltage $(I-V)$, capacitance-voltage $(C-V)$, and LCV measurements were conducted at room temperature. A lock-in amplifier was used to measure the capacitance. For DLOS, an alternating-current (AC) frequency of $5 \mathrm{kHz}$ was used, and a $10 \mathrm{kHz} \mathrm{AC}$ frequency was used for $C-V$ and LCV. A direct-current (DC) reverse bias was added to the lock-in sinusoid using a summing amplifier.

Only a brief overview of DLOS is provided here; details can be found elsewhere. ${ }^{7,12}$ DLOS analyzes the photocapacitance transient arising due to deeplevel photoemission in the depleted regions of the diode. For DLOS measurements, broadband illumination from a $150-\mathrm{W}$ Xe arc lamp was dispersed through a monochromator using appropriate mode-sorting filters to provide a photon energy $(h v)$ range of $1.20 \mathrm{eV}$ to $3.60 \mathrm{eV}$ in $20 \mathrm{meV}$ to $50 \mathrm{meV}$ increments. The photon flux varied between $8 \times$ $10^{15} \mathrm{~cm}^{-2} \mathrm{~s}^{-1}$ and $20 \times 10^{15} \mathrm{~cm}^{-2} \mathrm{~s}^{-1}$ over the scanned range. The spectral variation of the majority-carrier optical emission rate $e^{\mathrm{o}}(h v)$ of a deep level is obtained via DLOS from the time derivative of the photocapacitance at $t=0 \mathrm{~s}$, i.e., when illumination begins. ${ }^{7}$ Correcting $e^{\mathrm{o}}(h v)$ for the incident photon flux determines the spectral dependence of the deep-level optical cross-section $\left(\sigma_{0}\right)$. Fitting $\sigma_{\mathrm{o}}(h v)$ to an appropriate model ${ }^{13}$ that accounts for lattice coupling of the deep-level defect yields values for the optical ionization energy $\left(E_{\mathrm{o}}\right)$ and Franck-Condon shift $\left(d_{\mathrm{FC}}\right)$. Values of the fitted parameters were robust to changes in the fitted data range (yielding less than $50 \mathrm{meV}$ variation), as long as the threshold and saturation regions were included. DLOS measurements were conducted at an applied bias $V_{\mathrm{r}}$ by recording the photocapacitance transient for each photon energy using a $2 \mathrm{~ms}$ sampling time. For reverse-bias measurements, an electrical fill pulse of $-0.5 \mathrm{~V}$ was used to refill defect states throughout most of the $\operatorname{In}_{0.02} \mathrm{Ga}_{0.98} \mathrm{~N}$ UL while leaving the $\mathrm{In}_{0.17} \mathrm{Ga}_{0.83} \mathrm{~N}$ cap still depleted. The net areal deep-level density $\left(D_{t}\right)$ was found from LCV. ${ }^{8}$ Additional DLOS and LCV details are given in the "Experimental Results" section.

\section{EXPERIMENTAL RESULTS}

\section{Diode Characterization}

Dark $I-V$ and $C-V$ measurements were performed to verify the diodes' electrical behavior anticipated

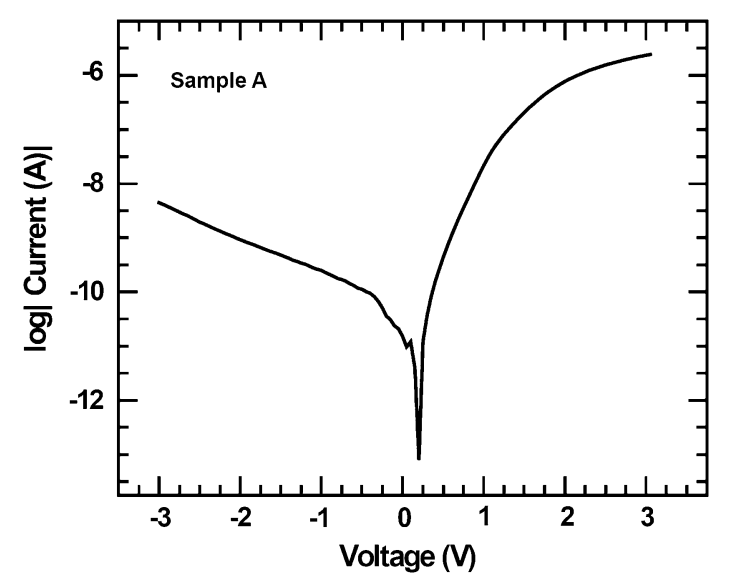

Fig. 2. Current-voltage scan of sample A.

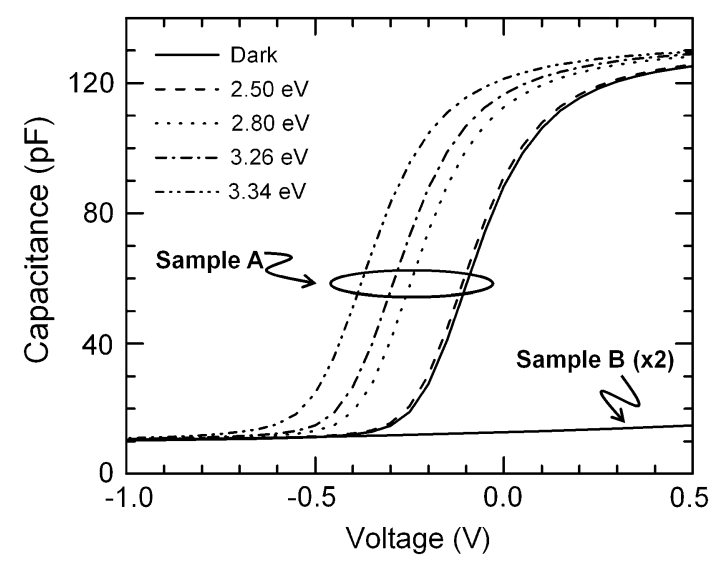

Fig. 3. Dark and lighted $C-V$ scans of the Schottky diodes.

from the 1D-SP simulations. Room-temperature $I-V$ data are shown in Fig. 2 for sample A, and similar behavior was observed for sample B. The barrier height of the nickel Schottky contact could not be determined from $I-V$ analysis owing to the excessively high series resistance. However, determining the Schottky barrier height is inconsequential to interpreting the DLOS measurement. Only the extent of the depletion region as a function of bias has bearing, which was determined experimentally by $C-V$.

Despite large series resistance and diode leakage, meaningful $C-V$ measurements were obtained for both DLOS samples and are displayed in Fig. 3. A phase angle $<-87^{\circ}$ between the capacitive and resistive components of the $\mathrm{AC}$ impedance was observed at each bias level, confirming an accurate capacitance measurement. ${ }^{14}$ Importantly, the plateau of the dark $C-V$ profile near $0 \mathrm{~V}$ for sample $\mathrm{A}$ suggests the existence of the anticipated 2DHG between the $\mathrm{In}_{0.17} \mathrm{Ga}_{0.83} \mathrm{~N}$ cap layer and the $\mathrm{In}_{0.02} \mathrm{Ga}_{0.98} \mathrm{~N}$ UL (Fig. 1). Formation of this $2 \mathrm{DHG}$ is critical because it enables DLOS depth dependence by screening the $\operatorname{In}_{0.02} \mathrm{Ga}_{0.98} \mathrm{~N}$ UL at $0 \mathrm{~V}$. The apparent charge profile (ACP) extracted from dark 


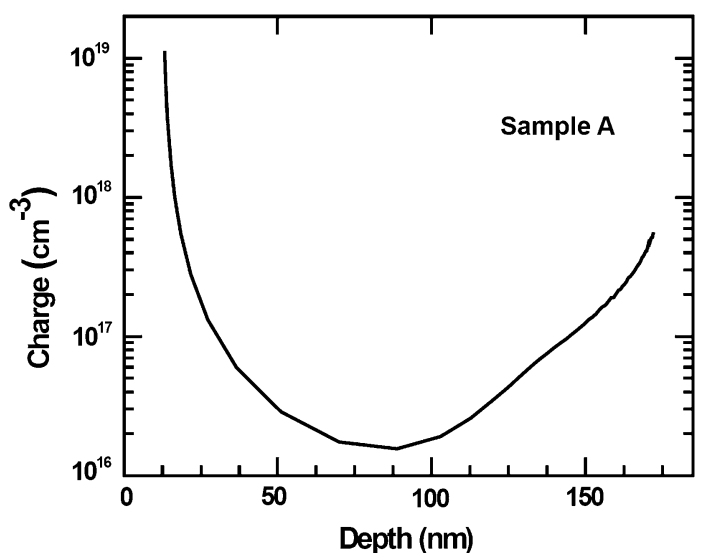

Fig. 4. Apparent charge profile of sample A determined from dark C-V.

$C-V$ profiling is presented in Fig. 4. The peak in the ACP observed at $\sim 13 \mathrm{~nm}$ below the surface corresponds to the 2DHGs at the $\mathrm{In}_{0.17} \mathrm{Ga}_{0.83} \mathrm{~N} /$ $\mathrm{In}_{0.02} \mathrm{Ga}_{0.98} \mathrm{~N}$ heterointerface. Integrating the ACP near the $\mathrm{In}_{0.17} \mathrm{Ga}_{0.83} \mathrm{~N} / \mathrm{In}_{0.02} \mathrm{Ga}_{0.98} \mathrm{~N}$ 2DHG determined a hole sheet density $p_{\mathrm{s}}$ of $1.6 \times 10^{12} \mathrm{~cm}^{-2}$. Conversely, $C-V$ measurement of sample $\mathrm{B}$ with the thinner InGaN cap had no plateau near $0 \mathrm{~V}$, implying no 2DHG formation at the near-surface heterointerface. This was expected, since, similar to AlGaN/GaN heterostructures, ${ }^{15}$ the InGaN cap thickness must exceed a critical value for a twodimensional carrier gas to form.

Figure 3 also displays LCV curves for sample A. The LCV curves were measured as a typical $C-V$ scan, but under constant illumination with monochromatic light. Though $h v$ exceeds the $\mathrm{In}_{0.17} \mathrm{Ga}_{0.83} \mathrm{~N}$ bandgap for the LCV curves recorded under $3.28 \mathrm{eV}$ and $3.34 \mathrm{eV}$ illumination, the phase angle of the impedance remained near $-90^{\circ}$ throughout the scans, confirming that free carriers generated in the $\mathrm{In}_{0.17} \mathrm{Ga}_{0.83} \mathrm{~N}$ cap layer did not undermine the accuracy of the measurement. Photoemission from defect states increases $p_{\mathrm{s}}$ and therefore the voltage required to pinch off the 2DHG. This effect shifts the LCV curve to more negative voltage, similar to the change in the threshold voltage for modulation-doped field-effect transistors due to the discharging of deep levels. ${ }^{16}$ The increasing shift in the LCV curves with increasing $h v$ demonstrates that the deep levels are distributed in energy in the InGaN bandgap. To quantify the properties of these defects and determine their location in the heterostructure, depthresolved DLOS was performed.

\section{Optical Spectroscopy of Defects}

Figure 5 shows DLOS spectra for sample A at $V_{\mathrm{r}}=0 \mathrm{~V}$ and for sample B at $V_{\mathrm{r}}=-2 \mathrm{~V}$, offset for clarity. From $C-V$ analysis, the depletion depth at $V_{\mathrm{r}}=0 \mathrm{~V}$ for sample $\mathrm{A}(14 \mathrm{~nm})$ was near the $\mathrm{In}_{0.17} \mathrm{Ga}_{0.83} \mathrm{~N} / \mathrm{In}_{0.02} \mathrm{Ga}_{0.98} \mathrm{~N}$ heterointerface, indicating

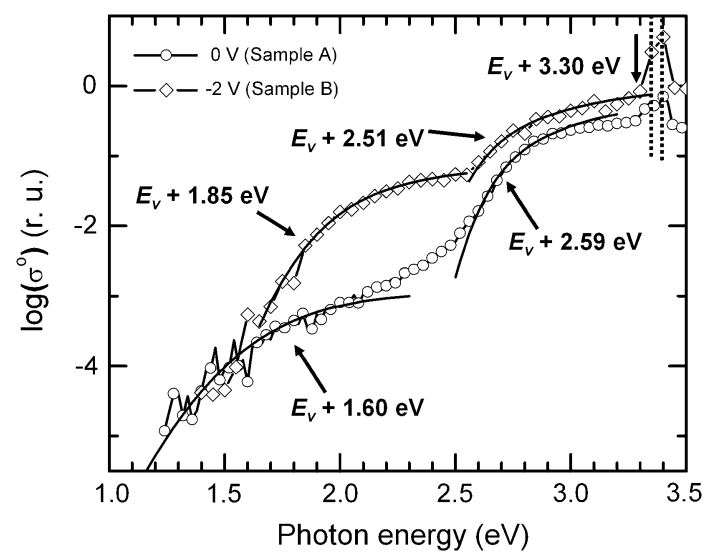

Fig. 5. DLOS scan at $V_{r}=0 \mathrm{~V}$ (sample A) and $V_{r}=-2 \mathrm{~V}$ (sample B). The symbols are data and the lines are theoretical fits to the model in Ref. ${ }^{13}$. The dotted lines denote the $3.36 \mathrm{eV} \ln _{0.02} \mathrm{Ga}_{0.98} \mathrm{~N}$ and $3.40 \mathrm{eV} p$-GaN band edges.

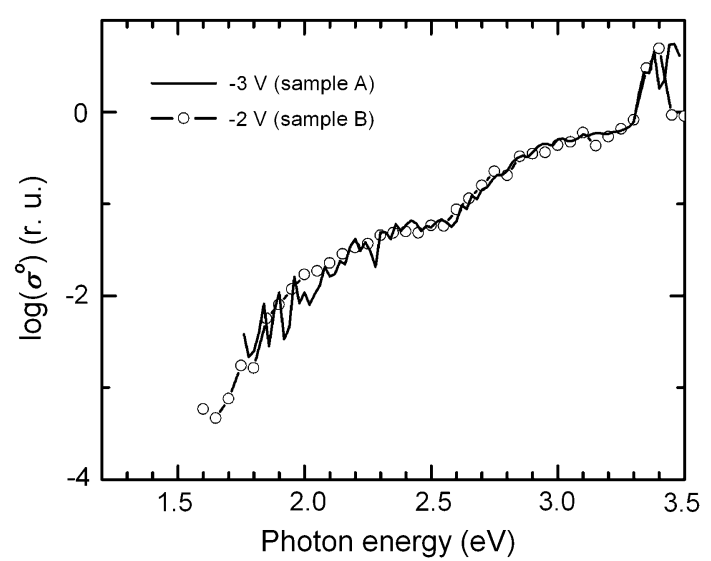

Fig. 6. DLOS scan at reverse bias for samples A and B.

primary DLOS sensitivity to deep-level defects located in the $\operatorname{In}_{0.17} \mathrm{Ga}_{0.83} \mathrm{~N}$ cap. For $V_{\mathrm{r}}=-2 \mathrm{~V}$, $C-V$ analysis determined that sample B was depleted well into the $\mathrm{In}_{0.02} \mathrm{Ga}_{0.98} \mathrm{~N}$ UL $(\sim 160 \mathrm{~nm}$ below the surface), suggesting that DLOS for this measurement condition was mainly sensitive to deep-level defects in the $\mathrm{In}_{0.02} \mathrm{Ga}_{0.98} \mathrm{~N} \mathrm{UL}$. Sample B was used for reverse-bias DLOS because its thinner $\mathrm{In}_{0.17} \mathrm{Ga}_{0.83} \mathrm{~N}$ cap improved sensitivity to the $\mathrm{In}_{0.02} \mathrm{Ga}_{0.98} \mathrm{~N}$ UL region. Figure 6 presents reverse-bias DLOS measurements for both samples, verifying similar defect spectra and enhanced resolution for sample B.

Selective sensitivity to defects in either the $\mathrm{In}_{0.17} \mathrm{Ga}_{0.83} \mathrm{~N}$ cap at $0 \mathrm{~V}$ or $\operatorname{In}_{0.02} \mathrm{Ga}_{0.98} \mathrm{~N}$ UL at $-2 \mathrm{~V}$ was confirmed by the dramatically different biasdependent DLOS spectra for $h v<2.9 \mathrm{eV}$ in Fig. 5 (the DLOS spectra for $h v>2.9 \mathrm{eV}$ is explained later in this section). Such starkly different deep-level defect spectra were anticipated for the $\operatorname{In}_{0.17} \mathrm{Ga}_{0.83} \mathrm{~N}$ cap and $\mathrm{In}_{0.02} \mathrm{Ga}_{0.98} \mathrm{~N}$ UL regions due to the large difference in indium content as well as their different growth temperatures and growth rates. This 


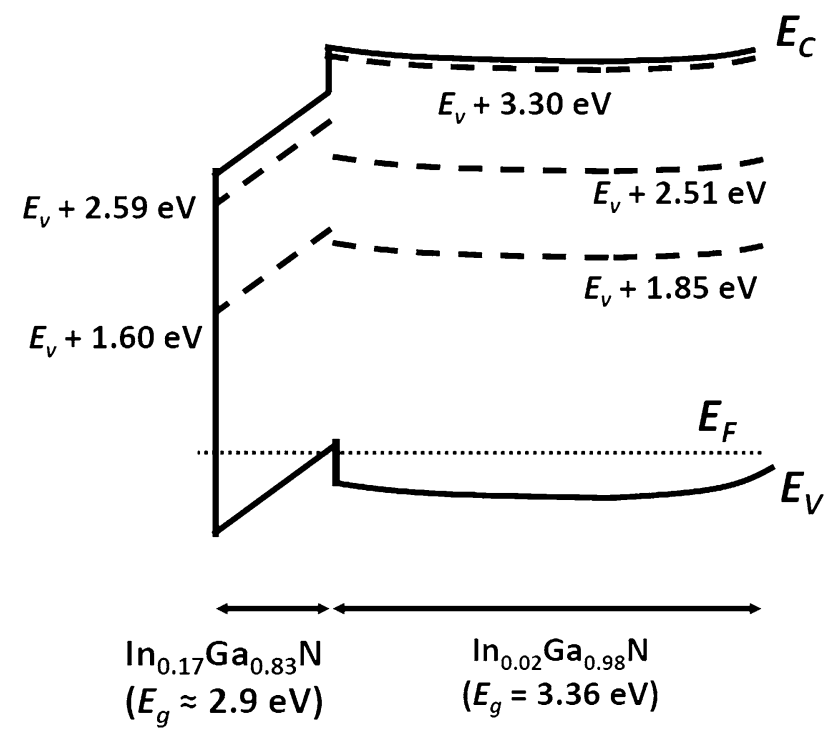

Fig. 7. Band diagram including defect levels for the $\ln _{0.17} \mathrm{Ga}_{0.83} \mathrm{GaN} /$ $\mathrm{In}_{0.02} \mathrm{Ga}_{0.98} \mathrm{~N} / p$-GaN:Mg heterostructure.

provides strong evidence that the electronic defect states observed for the different bias conditions are distinct and are located in separate regions of the heterostructure. If the DLOS measurements lacked depth resolution, identical, intermixed DLOS spectra would have been observed independent of bias. Figure 7 shows a band diagram of the DLOS heterostructures summarizing the spatial distribution of the observed defects and the energetic position of their bandgap states. Determination of the defect energy levels via DLOS is now discussed.

The $0 \mathrm{~V}$ DLOS spectrum for sample A is considered first. Saturation was observed near $2.9 \mathrm{eV}$ and was attributed to band-edge absorption of the $\mathrm{In}_{0.17} \mathrm{Ga}_{0.83} \mathrm{~N}$ cap, in agreement with previous results. ${ }^{5,17}$ Below the $2.9 \mathrm{eV} \operatorname{In}_{0.17} \mathrm{Ga}_{0.83} \mathrm{~N}$ bandedge energy, DLOS onsets near $1.2 \mathrm{eV}$ and $2.6 \mathrm{eV}$ for the $0 \mathrm{~V}$ measurement were ascribed to absorption by deep-level defects in the $\operatorname{In}_{0.17} \mathrm{Ga}_{0.83} \mathrm{~N}$. The $2.5 \mathrm{eV}<h v<2.9 \mathrm{eV}$ spectral features in Fig. 5 cannot be attributed to band tailing due to $\operatorname{In}_{0.17}$ $\mathrm{Ga}_{0.83} \mathrm{~N}$ Urbach tails because band-to-band absorption would give rise to a photocurrent rather than a photocapacitance.

The $1.2 \mathrm{eV}$ and $2.6 \mathrm{eV}$ DLOS onsets were fitted to a theoretical model ${ }^{13}$ to extract $E_{\text {o values of } 1.60 \mathrm{eV}}$ and $2.59 \mathrm{eV}$, respectively. The deep-level properties are summarized in Table I. The DLOS thresholds for the $1.60 \mathrm{eV}$ and $2.59 \mathrm{eV}$ levels were red-shifted compared with $E_{\text {o }}$ due to phonon-assisted photoemission, consistent with a sizable $d_{\mathrm{FC}}{ }^{7}$ All DLOS measurements produced positive photocapacitance, indicating majority-carrier (hole) photoemission, so all $E_{\mathrm{o}}$ values are referenced to $E_{\mathrm{v}}$. It is noted that, though deep-level photoemission occurs in the $\mathrm{In}_{0.17} \mathrm{Ga}_{0.83} \mathrm{~N}$ cap in the presence of a strong electrical field, the optical transitions involving a localized carrier are far less affected by the FranzKeldysh effect than are band-to-band transitions. ${ }^{18}$ Thus, DLOS accurately determines $E_{0}$ despite the strong electric field at $0 \mathrm{~V}$.

The $V_{\mathrm{r}}=-2 \mathrm{~V}$ DLOS spectrum for sample $\mathrm{B}$ is now considered, where the observed deep-level defects are associated with the $\operatorname{In}_{0.02} \mathrm{Ga}_{0.98} \mathrm{~N} \mathrm{UL}$. Focusing first on the $h v>3.30 \mathrm{eV}$ range, saturations in the spectra at $3.36 \mathrm{eV}$ and $3.40 \mathrm{eV}$ mark the $\mathrm{In}_{0.02} \mathrm{Ga}_{0.98} \mathrm{~N}$ and $p$-GaN:Mg band edge, respectively. The $3.36 \mathrm{eV}$ and $3.40 \mathrm{eV}$ band edges were also weakly evident for DLOS of sample A measured at $0 \mathrm{~V}$. The two DLOS onsets near $1.70 \mathrm{eV}$ and $2.50 \mathrm{eV}$ for the $-2 \mathrm{~V}$ DLOS spectrum were fitted to the same theoretical model ${ }^{13}$ as before to extract $E_{\mathrm{o}}=1.85 \mathrm{eV}$ and $2.51 \mathrm{eV}$, respectively. The $E_{\mathrm{v}}+1.85 \mathrm{eV}$ and $E_{\mathrm{v}}+2.51 \mathrm{eV}$ levels exhibited thresholds that were red-shifted relative to their respective $E_{\mathrm{o}}$, indicating significant $d_{\mathrm{FC}}$ values. Conversely, the sharp onset at $3.30 \mathrm{eV}$ indicates a deep level with $E_{\mathrm{o}}=3.30 \mathrm{eV}$ and negligible $d_{\mathrm{FC}}{ }^{19}$

\section{Determination of Deep-Level Density}

The areal deep-level density was determined using LCV. ${ }^{8}$ In the case of a slowly varying background charge density, the deep-level concentration profile can be obtained by LCV from the change in the ACP when the defect is photoionized. ${ }^{8}$ In the present case, the multiple $2 \mathrm{DHG}$ produce a rapidly varying ACP, so only $D_{\mathrm{t}}$ could be determined. Assuming that the defects are uniformly distributed and treating the regions between the nickel metal and 2DHGs as parallel-plate capacitors, the areal defect density is calculated as

$$
D_{\mathrm{t}}=(2 / q A) \int_{0}^{V} C \mathrm{~d} V
$$

Table I. Summary of defect location within the heterostructure, defect parameters, and employed LCV photon energies, where "Dark" means that the dark $C-V$ value for space charge was used

\begin{tabular}{|c|c|c|c|c|}
\hline Location & $E_{\mathrm{o}}(\mathrm{eV})$ & $d_{\mathrm{FC}}(\mathrm{eV})$ & $\operatorname{LCV} h v(\mathrm{eV})$ & $D_{\mathrm{t}}\left(\mathrm{cm}^{-2}\right)$ \\
\hline $\mathrm{In}_{0.17} \mathrm{Ga}_{0.83} \mathrm{~N}$ & $E_{\mathrm{v}}+1.60$ & 0.63 & Dark-2.20 & $\geq 6.4 \times 10^{10}$ \\
\hline $\mathrm{In}_{0.17} \mathrm{Ga}_{0.83} \mathrm{~N}$ & $E_{\mathrm{v}}+2.59$ & 0.09 & $2.50-2.80$ & $\geq 3.0 \times 10^{12}$ \\
\hline $\mathrm{In}_{0.02} \mathrm{Ga}_{0.98} \mathrm{~N}$ & $E_{\mathrm{v}}+1.85$ & 0.28 & Dark-2.50 & $\leq 1.5 \times 10^{10}$ \\
\hline $\mathrm{In}_{0.02} \mathrm{Ga}_{0.98} \mathrm{~N}$ & $E_{\mathrm{v}}+2.51$ & 0.08 & $2.50-3.26$ & $\leq 1.4 \times 10^{11}$ \\
\hline $\mathrm{In}_{0.02} \mathrm{Ga}_{0.98} \mathrm{~N}$ & $E_{\mathrm{v}}+3.30$ & - & $3.26-3.34$ & $\leq 1.4 \times 10^{12}$ \\
\hline
\end{tabular}


where $q$ is the Coulomb charge and $A$ is the diode area. The $D_{\mathrm{t}}$ values are regarded as lower limits because, for photon energies greater than half the bandgap, simultaneous electron and hole optical emission can occur and leave the defect partially occupied despite the optical pumping. ${ }^{8}$

Individual $D_{\mathrm{t}}$ values were measured using LCV by successive optical stimulation of each defect level in turn. For example, $D_{\mathrm{t}}$ for the $E_{\mathrm{v}}+3.30 \mathrm{eV}$ level was measured from the increase in space-charge density, as measured by LCV scans using $3.24 \mathrm{eV}$ and $3.34 \mathrm{eV}$ illumination. Under $3.24 \mathrm{eV}$ illumination, all levels except $E_{\mathrm{v}}+3.30 \mathrm{eV}$ are mostly depopulated, so the relative increase in space charge under $3.34 \mathrm{eV}$ illumination is mainly due to photoexcitation of the $E_{\mathrm{v}}+3.30 \mathrm{eV}$ level. The measured $D_{\mathrm{t}}$ values for all deep levels are given in Table I, along with the corresponding LCV photon energies.

The density of deep-level defects with closely spaced $E_{\mathrm{o}}<2.9 \mathrm{eV}$ could not be completely delineated among those in the $\mathrm{In}_{0.17} \mathrm{Ga}_{0.83} \mathrm{~N}$ cap and the $\mathrm{In}_{0.02} \mathrm{Ga}_{0.98} \mathrm{~N}$ UL, because LCV does not have depth selectivity as applied in this study. Upper bounds of $D_{\mathrm{t}}$ for the $E_{\mathrm{v}}+1.85 \mathrm{eV}$ and $E_{\mathrm{v}}+2.51 \mathrm{eV} \operatorname{In}_{0.02-}$ $\mathrm{Ga}_{0.98} \mathrm{~N}$-related defect levels were measured using LCV scans for sample B, where contributions to $D_{\mathrm{t}}$ from $\mathrm{In}_{0.17} \mathrm{Ga}_{0.83} \mathrm{~N}$-related defects were minimized because of the reduced $\operatorname{In}_{0.17} \mathrm{Ga}_{0.83} \mathrm{~N}$ cap thickness. Lower bounds of $D_{\mathrm{t}}$ for the $E_{\mathrm{v}}+1.60 \mathrm{eV}$ and $E_{\mathrm{v}}+2.59 \mathrm{eV} \quad \mathrm{In}_{0.17} \mathrm{Ga}_{0.83} \mathrm{~N}$-related defect levels were determined by performing LCV scans for sample A over the appropriate photon energy range and subtracting $D_{\mathrm{t}}$ measured from LCV scans of sample B taken over the same photon energy range. In this way, the contributions to $D_{\mathrm{t}}$ from defects in the $\mathrm{In}_{0.02} \mathrm{Ga}_{0.98} \mathrm{~N}$ UL were eliminated from the measurement.

\section{DISCUSSION}

Determining the physical location, energy level in the bandgap, and density of the deep levels in the heterostructure helps to understand the potential role of defect states in LED devices. For instance, the growth conditions and presumably the defect incorporation of the $\operatorname{In}_{0.17} \mathrm{Ga}_{0.83} \mathrm{~N}$ cap are nominally identical to those of an InGaN well of an LED. Considering the $\operatorname{In}_{0.17} \mathrm{Ga}_{0.83} \mathrm{~N}$-related defects, the large density of the $E_{\mathrm{v}}+2.59$ deep state compared with the $E_{\mathrm{v}}+1.60 \mathrm{eV}$ level might suggest that the former would have a greater adverse effect on the radiative efficiency in a MQW. However, the $E_{\mathrm{v}}+$ $1.60 \mathrm{eV}$ level is expected to be a more efficient NRC because of its energetic position near the middle of the $\operatorname{In}_{0.17} \mathrm{Ga}_{0.83} \mathrm{~N}$ bandgap. The $E_{\mathrm{v}}+2.59 \mathrm{eV}$ deep level is likely to interact solely with the conduction band as an electron trap rather than behave as an NRC. Nevertheless, an electron trap can reduce LED efficiency by reducing the free carrier density available to produce the desired emission wavelength. It is noted that additional defects in InGaN well layers beyond those that are reported here can incorporate during subsequent high-temperature growth of $\mathrm{GaN}$ regions to form a $\mathrm{MQW}$ structure or a $p-i-n$ LED structure. ${ }^{20}$

The $E_{\mathrm{v}}+1.85 \mathrm{eV}, E_{\mathrm{v}}+2.51 \mathrm{eV}$, and $E_{\mathrm{v}}+3.30 \mathrm{eV}$ defects located in the InGaN UL would be spatially removed from the MQWs region in an LED. Nonetheless, these deep levels can act as trapping and compensation centers that inhibit carrier transport to the QWs. Such parasitic effects would increase the electrical resistance and decrease the overall efficiency of an LED.

Assessing the similarities among the present DLOS results and prior defect spectroscopy investigations of InGaN films and InGaN/GaN LEDs offers insight into the possible physical origins of the observed defects. The thermal ionization energy $\left(E_{\mathrm{th}}\right)$ of the $\mathrm{In}_{0.17} \mathrm{Ga}_{0.83} \mathrm{~N}$-related $E_{\mathrm{v}}+2.59 \mathrm{eV}$ $\left(d_{\mathrm{FC}}=0.09\right)$ deep level relative to the conductionband minimum $\left(E_{\mathrm{c}}\right)$ is approximately $E_{\mathrm{g}}-E_{\mathrm{o}}+$ $d_{\mathrm{FC}}=E_{\mathrm{c}}-0.36 \mathrm{eV}$. This $E_{\mathrm{th}}$ energy is in close agreement with a deep level at $E_{\mathrm{c}}-0.4 \mathrm{eV}$ detected via DLTS in an $\operatorname{In}_{0.14} \mathrm{Ga}_{0.86} \mathrm{~N}$ epilayer that was ascribed to a point defect. ${ }^{6}$ On the other hand, $E_{\text {th }}=0.36 \mathrm{eV}$ is also consistent with a CL defect band centered at $2.45 \mathrm{eV}$ in an $\mathrm{In}_{0.17} \mathrm{Ga}_{0.83} \mathrm{~N}$ epilayer that was associated with surface pits centered at threading dislocations. ${ }^{5}$ Thus, ascription of the $E_{\mathrm{v}}+2.59 \mathrm{eV}$ level to either a point or extended defect could be made in light of previous work on InGaN defects. The $E_{\mathrm{v}}+1.60 \mathrm{eV}$ bandgap state does not appear similar to any previously reported InGaN deep level, which is not surprising considering that it is too deep to be observed using DLTS, and it is likely an NRC unobservable by luminescence.

Comparison of the defect levels observed in the UID $\mathrm{In}_{0.02} \mathrm{Ga}_{0.98} \mathrm{~N}$ UL with those expected for $p$-GaN is warranted, because this layer has a relatively low indium content and the Fermi level lies near $E_{\mathrm{v}}$. The thermal ionization energy for the $E_{\mathrm{v}}+1.85 \mathrm{eV}\left(d_{\mathrm{FC}}=0.28\right)$ deep state lies near the thermodynamic transition energies calculated for the nitrogen interstitial and nitrogen antisite defects in GaN, while the $E_{\text {th }}$ for the $E_{\mathrm{v}}+2.51 \mathrm{eV}$ level $\left(d_{\mathrm{FC}}=0.09 \mathrm{eV}\right)$ lies near energy levels calculated for the gallium interstitial and gallium antisite defects in $\mathrm{GaN}^{21}$ However, the large calculated formation energies of these native defects in $\mathrm{GaN}^{21}$ suggest that extrinsic defects are a more likely source for the $E_{\mathrm{v}}+1.85$ and $E_{\mathrm{v}}+2.51 \mathrm{In}_{0.02} \mathrm{Ga}_{0.98} \mathrm{~N}$ defect levels. The energy of the $E_{\mathrm{v}}+1.85 \mathrm{eV}$ defect level is similar to the "OLP1" deep level reported in MOCVD-grown GaN:Mg, ${ }^{22,23}$ suggesting a common physical source such as a threading dislocation, carbon or oxygen impurities, or even $\mathrm{Mg}$ diffused into the UID $\mathrm{In}_{0.02} \mathrm{Ga}_{0.98} \mathrm{~N}$ from the adjacent $p$-GaN region. Based on the $3.36 \mathrm{eV}$ bandgap of the $\operatorname{In}_{0.02}$ $\mathrm{Ga}_{0.98} \mathrm{~N} \mathrm{UL}$, the $E_{\mathrm{v}}+3.30 \mathrm{eV}\left(E_{\mathrm{c}}-0.06 \mathrm{eV}\right)$ level is likely due to the nitrogen vacancy, which has been 
assigned to a shallow donor level $0.07 \mathrm{eV}$ from $E_{\mathrm{c} .}{ }^{24}$ The nitrogen vacancy defect could also incorporate as a shallow donor level in the $\operatorname{In}_{0.17} \mathrm{Ga}_{0.83} \mathrm{~N}$ cap layer, but such a level would be difficult to observe due to the prominence of the $E_{\mathrm{v}}+2.59 \mathrm{eV}$ level.

\section{CONCLUSIONS}

Deep-level defects were studied in $\mathrm{In}_{0.17} \mathrm{Ga}_{0.83} \mathrm{~N} /$ $\mathrm{In}_{0.02} \mathrm{Ga}_{0.98} \mathrm{~N} / p$-GaN heterostructures where the $\mathrm{In}_{x} \mathrm{Ga}_{1-x} \mathrm{~N}$ layers were grown under nominally the same conditions as used for a MQW structure. Using depth-resolved DLOS combined with LCV, the optical ionization energy, deep-level density, and location in the heterostructure were determined for the observed defect states. These defects are expected to reflect those incorporated in InGaN/ GaN QWs, so this work provides important insight into the potential influence of defects on QW radiative efficiency. Deep levels at $E_{\mathrm{v}}+1.60 \mathrm{eV}$ and $E_{\mathrm{v}}+2.59 \mathrm{eV}$ were observed for the $\mathrm{In}_{0.17} \mathrm{Ga}_{0.83} \mathrm{~N}$ region that emulates the well region of an $\mathrm{InGaN} /$ GaN QW. The $E_{\mathrm{v}}+1.60 \mathrm{eV}$ level is suspected to be an efficient NRC based on its energetic position near the middle of the $\mathrm{In}_{0.17} \mathrm{Ga}_{0.83} \mathrm{~N}$ bandgap. Direct observation of a mid-bandgap $\operatorname{In}_{0.17} \mathrm{Ga}_{0.83} \mathrm{~N}$ deep level using DLOS is significant, because this level is unlikely to be observed via more common methods such as luminescence or DLTS. The $\operatorname{In}_{0.02} \mathrm{Ga}_{0.98} \mathrm{~N}$ UL presented defect levels at $E_{\mathrm{v}}+1.85 \mathrm{eV}, E_{\mathrm{v}}+$ $2.51 \mathrm{eV}$, and $E_{\mathrm{v}}+3.30 \mathrm{eV}$, where the latter is suggested to be the nitrogen vacancy.

\section{ACKNOWLEDGEMENTS}

DLOS measurements at $0 \mathrm{~V}$, modeling, and growth were supported by EERE/NETL, US Department of Energy under Project Number M6802094 (Brian Dotson and Sean Evans, Program Managers), and reverse-bias DLOS measurements were supported by Sandia's Solid-State Lighting Science Energy Frontier Research Center, funded by the US Department of Energy, Office of Basic Energy Sciences. Sandia is a multiprogram laboratory operated by Sandia Corporation, a Lockheed Martin Company, for the US Department of Energy's
National Nuclear Security Administration under Contract No. DE-AC04-94AL85000.

\section{REFERENCES}

1. M.H. Crawford, IEEE J. Sel. Top. Quant. Electron. 15, 1028 (2009).

2. L. Rigutti, A. Castaldini, M. Meneghini, and A. Cavallini, Semicond. Sci. Technol. 23, 025004 (2008).

3. F. Rossi, M. Pavesi, M. Meneghini, G. Salviati, M. Manfredi, G. Meneghesso, A. Castaldini, A. Cavallini, L. Rigutti, U. Strass, U. Zehnder, and E. Zanoni, J. Appl. Phys. 99, 053104 (2006).

4. L. Rigutti, A. Castaldini, and A. Cavallini, Phys. Rev. B 77, 015312 (2008).

5. S. Srinivasan, F. Bertram, A. Bell, F.A. Ponce, S. Tanaka, H. Omiya, and Y. Nakagawa, Appl. Phys. Lett. 80, 550 (2002).

6. C.B. Soh, S.J. Chua, P. Chen, D.Z. Chi, W. Liu, and H. Hartono, Thin Solid Films 515, 4509 (2006).

7. A. Chantre, G. Vincent, and D. Bois, Phys. Rev. B 23, 5335 (1981).

8. A. Armstrong, A.R. Arehart, and S.A. Ringel, J. Appl. Phys. 97, 083529 (2005).

9. M. Grundmann, BANDENG. http://my.ece.ucsb.edu/mgrund mann/bandeng.htm.

10. F. Bernardini, V. Fiorentini, and D. Vanderbilt, Phys. Rev. B 56, R10024 (1997).

11. J.K. Son, S.N. Lee, T. Sakong, H.S. Paek, O. Nam, Y. Park, J.S. Hwang, J.Y. Kim, and Y.H. Cho, J. Cryst. Growth 287, $558(2006)$

12. A. Hierro, D. Kwon, S.A. Ringel, S. Rubini, E. Pelucchi, and A. Franciosi, J. Appl. Phys. 87, 730 (2000).

13. R. Passler, J. Appl. Phys. 96, 715 (2004).

14. J. Wiley and G. Miller, IEEE Trans. Electron. Dev. ED-22, 265 (1975).

15. J.P. Ibbetson, P.T. Fini, K.D. Ness, S.P. DenBaars, J.S Speck, and U.K. Mishra, Appl. Phys. Lett. 77, 250 (2000).

16. A.J. Valois and G.Y. Robinson, IEEE Electron. Dev. Lett. EDL-4, 360 (1983).

17. R.W. Martin, P.G. Middleton, K.P. O'Donnell, and W. Van der Stricht, Appl. Phys. Lett. 74, 263 (1999).

18. C. Wetzel, T. Takeuchi, H. Amano, and I. Akasaki, J. Appl. Phys. 85, 3786 (1999).

19. A. Armstrong, A.R. Arehart, D. Green, U.K. Mishra, J.S. Speck, and S.A. Ringel, J. Appl. Phys. 98, 053704 (2005).

20. P. Kozodoy, A. Abare, R.K. Sink, M. Mack, S. Keller, S.P. DenBaars, U.K. Mishra, and D. Steigerwald, Mater. Res. Soc. Symp. Proc. 468, 481 (1997).

21. S. Limpijumnong and C.G. Van de Walle, Phys. Rev. B 69, 035207 (2004).

22. W. Götz, N.M. Johnson, and D.P. Bour, Appl. Phys. Lett. 68, 3470 (1996).

23. A. Armstrong, G. Thaler, and D.D. Koleske, J. Appl. Phys. 105, 043712 (2009).

24. D.C. Look, G.C. Farlow, P.J. Drevinsky, D.F. Bliss, and J.R. Sizelove, Appl. Phys. Lett. 83, 3525 (2003). 